While these may not all have been statistically watertight studies, they did show a reduced rather than an increased incidence of thromboebolic disease. Hougie ${ }^{2}$ in an excellent review article quotes the Puerto Rican study $^{3}$ designed especially to determine the effects of oral contraceptive agents on the incidence of thromboembolic disease in which 9,898 patients were randomly allocated to the contraceptive pill or to other contraceptive methods and followed up. This very large prospective study also failed to show an increased risk of thrombophlebitis among pill users. It may be argued that these surveys are dealing with different population groups, but it is by no means proved that "clotting [is] provoked by oral contraceptives." - I am, etc.,

St. Bartholomew's Hospital,

MichaEL KLABER

London E.C.1

1 Drill, V. A., Fournal of the American Medical Association, 1972, 219, 583.

Hougie, C., American Heart fournal, 1973, 85, 538.

3 Fuertes-de la Haba, A., Curet, J. O., Pelegrina, I., and Bangdiwald, I., Obstetrics and Gynecology, $1971,38,259$.

\section{Anaemia in Beta-thalassaemic Carriers}

SIR,-We are very interested in the question of anaemia occurring in heterozygous betathalassaemic subjects. Thus we are grateful to Dr. H. H. M. Knox-Macauley and his colleagues (21 July 1973, p. 150), who report a reduced haemoglobin level in betathalassaemic carriers. Two of us had already reported similar results in heterozygous betathalassaemic children of both sexes. ${ }^{1}$ Nevertheless, we think that neither report proves whether symptomless beta-thalassaemic subjects are anaemic or not, since the study of Dr. Knox-Macauley and his colleagues was concerned with patients referred to hospital and ours related to a child inpatient population. Similarly, no conclusive evidence is provided by a recent investigation performed in Thailand, ${ }^{2}$ since no information concerning the age of the subjects examined is given. We have therefore determined the haemoglobin levels of groups of symptom-free heterozygous beta-thalassaemic males (age 15-60 years) and females (15-52 years) compared with normal controls. The results are given in the table.

These data show a significant decrease in the mean haemoglobin level in betathalassaemic carriers of both sexes. According to one authority ${ }^{3}$ the lower limits of normal haemoglobin content at sea level (as in the present investigation) are 14 and 12 $\mathrm{g} / 100 \mathrm{ml}$ for males and fermales respectively. The haemoglobin level in 86 of the 87 betathalassaemic males examined by us was below $14 \mathrm{~g} / 100 \mathrm{ml}$, while in 61 of the 70 beta-thalassaemic females it was less than $12 \mathrm{~g} / 100 \mathrm{ml}$. Our study therefore leads to the conclusion that anaemia is quite a common finding in beta-thalassaemic carriers.
In our opinion this pattern of anaemia could be related to the reduced mean corpuscular haemoglobin content ${ }^{4}$ brought about by a decrease of both alpha- and betachain production, ${ }^{5}$ with impaired haem biosynthesis $^{6}$ and increased haemolysis.? -We are, etc.,

Giuseppe Castaldi GIORGIO ZAVAGLI

GIOVANNI AMBRoso

Clinica Medica,

BRUNo Dallapiccola

Medicina del Lavoro,
Università di Ferrara,

Franco Trotta

Ferrara, Italy

1 Castaldi, G., and Zavagli, G., Lancet, 1972 2, 1254

2 Pootrakul, P., Wasi, P., and Na-Nakorn, S., British fournal of Haematology, 1973, 24, 703. 3 Committee on Iron Deficiency, fournal of the American Medical Association, 1968, 203, 407. Kan, Y. W., and Nathan, D. G., fou Clinical Investigation, 1970, 49, 635. Kan, Y. W., Nathan, D. G., and Lodish, H. F., Fournal of Clinical Investigation, 1972, 51, 1906.
Lyberatos, C., et al., Acta Haematologica, 1972,

M7, 164 . U., Gallo, E., Ricco, G., Pich, G., and Stratta, O., Fallo, E., Rirst Meeting of G., Pich, G., and of International Society of Haematology, Milan, 1971 (abstracts, p. 36).

\section{Steroid Aerosols in Asthma}

SIR,-The disturbing incidence of candida infections of the pharynx and the larynx reported by Dr. M. K. McAllen and others (2 February, p. 171) is not universal. I have treated 149 patients with an aerosol of beclomethasone dipropionate and in 80 the period of observation has been for 20-30 months. ${ }^{1}$ In five cases sore throat, huskiness, or hoarseness was reported. In one case Candida albicans was grown but quickly disappeared with treatment with nystatin lozenges. The patient has continued for a further 12 months with a dose of $400 \mu \mathrm{g}$ of beclomethasone daily without trouble. In the remaining four cases postnasal swabs were negative but symptoms disappeared after the dose of aerosol had been decreased to 300 or $200 \mu \mathrm{g}$ per day. Despite careful questioning, none of the other patients has complained of a sore throat or hoarseness.

Other findings may be of interest. After 18 months of treatment with the aerosol five patients have been weaned completely without relapse of asthma, but in 25 others the symptoms recurred and they have had to continue, usually at a dose of 200-300 $\mu \mathrm{g}$ daily. Seventeen patients claim that they have had more frequent attacks of purulent bronchitis than before treatment; 11 have had to have occasional courses of oral prednisolone and antibiotics together, but have continued with good function between attacks. Four patients who had originally been well controlled have relapsed and failed to respond to further treatment and are maintained now on oral steroids. Originally 47 out of 75 patients who had been maintained on systemic steroids pre- viously were weaned successfully from oral steroids and received at least equal benefit from the aerosol. Two only of these patients have relapsed and have had to resume oral steroids daily. No other untoward effects have been noted. Serum cortisol levels have remained normal in all patients who had not previcusly received oral steroids and in the 45 completely weaned successfully from oral steroids.

Regular use of the beclomethasone aerosol remains a significant advance in the safe management of asthma as long as (1) the dose is kept to the minimum required and (2) the patient is carefully instructed how to use the aerosol, otherwise most is expended in the mouth and throat.-I am, etc.,

Hertford and Bishop's Stortford Chest Clinics,

A. Pines Hertford

1 Pines, A., Practitioner, 1973, 211, 86.

\section{Clinical Diagnosis of Reye's Syndrome}

SIR,-Your leading article on this subject (11 August, p. 308) is timely and emphasizes the need to consider Reye's syndrome in any child with an encephalopathy of no apparent cause.

Of great concern to clinicians in establishing the diagnosis of the disease are the guidelines advocated in your article, which are largely drawn from the prospective studies of Glasgow et al. ${ }^{1-3}$ In these studies of patients with encephalopathy and fatty visceral degeneration in Thailand no mention is made of the presence or lack of toxic quantities of aflatoxin in the urine of the patients or in the tissues in fatal cases. In a series of earlier articles from Thailand on the epidemiology, toxicology, and clinical study of a Reye's-like syndrome the toxin of Aspergillus flavus was implicated as the aetiological factor. ${ }^{+-7}$ A striking clinical, biochemical, and pathological corollary to the human disease can be produced in the juvenile monkey by the administration of a purified toxin derived from cultures of fungi contaminating foodstuffs ingested by viotims.

Clarification of this point about the presence or absence of toxic amounts of aflatoxin in the fluids and tissues of affected patients is of fundamental importance before criteria developed for the aflatoxin-related diseases are adopted for the diagnosis of a disorder not due to aflatoxins. Differentiation of these two syndromes can be made not only on toxicological grounds but also pathologically and clinically. While there are many similarities, clinical differences can be found," especially the precipitous course in the Thai disorder, which is often heralded by seizures, which progressed to status epilepticus in about $50^{\circ}:$ of one series of 67 cases. 4 Hypoglycaemia is also more frequent in the Thai disease, being found in $75 \%$ in one series 1 and in $99 \%$ in another. In three of Glasgow et al.'s 43 cases consciousness was regained on administration of intravenous glucose g $^{13}$ and in several others improvement such as increased pupillary responses were seen. From these observations they concluded that hypoglycaemia played an important role in the development of the encephalopathy in their patients. The hypoglycaemia in Reye's syndrome is not influenced by infusions of 